\title{
Soft Switching of Three-Phase AC to DC CIHRC with Wireless Power Transfer (WPT) Function
}

\author{
Rahimi Baharom \\ Faculty of Electrical Engineering, Universiti Teknologi MARA, Selangor, Malaysia
}

\begin{tabular}{|c|c|}
\hline Article Info & ABSTRACT \\
\hline Article history: & \multirow{6}{*}{$\begin{array}{l}\text { This paper presents the verification of soft switching condition for three- } \\
\text { phase AC to DC current injection hybrid resonant converter (CIHRC) with } \\
\text { wireless power transfer (WPT) function. Details on the operation of current } \\
\text { injection technique with the lossless zero voltage switching (ZVS) condition } \\
\text { on shaping the high power factor of supply current waveforms are presented. } \\
\text { With a suitable high switching frequency operation, the proposed resonant } \\
\text { converter is capable to operate with ZVS conditions, thus, allowing reduction } \\
\text { in the size of inductive and magnetic components. Selected results are also } \\
\text { presented to verify the lossless ZVS condition for three-phase AC-DC } \\
\text { CIHRC with WPT function. }\end{array}$} \\
\hline Received May 11, 2018 & \\
\hline Revised Jul 22, 2018 & \\
\hline Accepted Aug 8, 2018 & \\
\hline Keyword: & \\
\hline $\begin{array}{l}\text { Current injection technique } \\
\text { Three-phase rectifier }\end{array}$ & \\
\hline
\end{tabular}

Copyright () 2018 Institute of Advanced Engineering and Science. All rights reserved.

\section{Corresponding Author:}

Rahimi Baharom,

Faculty of Electrical Engineering,

Universiti Teknologi MARA,

40450 Shah Alam, Selangor, Malaysia.

Email: rahimi6579@gmail.com

\section{INTRODUCTION}

The proliferation of power electronic system has sparked the rectifier as an important approach to obtain the DC output voltage from an input AC voltage [1], [2]. Due to the merits such as low switch stress, low output ripple and better power factor were among the factor of three-phase variants being more preferred as compared to single-phase variants [1]. Conventional three-phase rectifier circuit as shown in Figure 1 (a) used diode-bridge to perform their operations [3]. However, it will produce undesirable distorted line current as shown in Figure 1 (b) with low power factors which could possibly cause harmonic pollution in the power supply system [2]-[5]. Moreover, the additional harmonic losses in the utility system were capable to excite electrical resonance, resulting in large over voltages [2]. Thus, in order to avoid the harmonic pollution of the utility system, several standards such as the IEEE Std. 519 have been developed and were being enforced on the harmonic content of the current and voltage drawn by power electronic converters [1], [4], [6]. To solve this problem, other options such as power factor correction (PFC) converters and active power filter technique to compensate for the harmonic current generated by the diode rectifiers have been developed extensively [3].

With stringent power quality regulations, PFC has become an active research topic in power electronics. In line with this trend, there were many topologies or techniques proposed and developed to improve high power factor three-phase rectifier [7]. Recently, among all of these techniques, the current injection rectifier was the most attractive in applications of AC to DC converter topologies. This technique was known for its high performances in terms of power factor, efficiency, reliability, lightweight feature, output voltage regulation and simple upgrading to the existing three-phase rectifier circuit [8]-[11]. In addition, the current injection technique was more practical due to its simplicity [12]. Basically, there are 
three types of current injection techniques namely, the third harmonics sinusoidal current injection, the optimal current injection and the square-wave current injection [9], [13].

The third-harmonic current injection is a popular method to effectively solve the input current harmonic content of three-phase diode bridge rectifiers [14]. This technique was first realised by Bird et al. in 1969 [15]. Further investigations on this technique have been carried out by Ametani [16]. In this technique, the current waveform on the DC windings of the converter transformer was modified by injecting a harmonic current at a particular frequency. As a result of this, the original current waveform on these windings was deformed by the injected current. Hence, through a proper shaping of the supply current waveform, it was possible to reduce their harmonic components [16].

The three-phase current injection rectifier as shown in Figure 2 typically consists of three main parts, a diode bridge rectifier, a modulation circuit and a distribution circuit. The three-phase diode bridge rectifier was used to rectify an electrical energy from an AC to a DC form. The second part of the three-phase current injection rectifier is the modulation circuit which was a major part of this technique. The principle function of a modulation circuit was to shape the DC current at the output of the diode bridge rectifier by generating the third harmonic current which can be implemented using a passive or an active approach [17]. The purpose of the current shaping approach is to control the amount of current that flowed through injector and the harmonic content of injected current. The concept of this approach was based on a prior assumption that to create a symmetric three-phase harmonic-free rectification. In this way, all the three-phase input should observe the same impedance, linear and purely resistive [18]. The distribution circuit's function is to inject a zero-sequence current into the AC supply voltage. This will prevent the discontinuity of the AC supply current waveform resulting in high power factor with low total harmonic distortion (THD) level [19]. Several other approaches could be implemented for the distribution circuit in three-phase current injection rectifier. This includes the zigzag-connected transformer, inductor-capacitor injectors, a specific magnetic device injector, a delta-star transformer and a bidirectional switches. These approaches were used to inject the current generated by the modulation circuit to the AC input side of the controlled rectifier circuit [17], [20].

The series configuration of the current injection resonant converter (CISRC) as shown in Figure 3 was first realised by Cross [21]. In such a circuit, an autotransformer was employed to step up the output voltage which is connected at the output of the single-phase high-frequency inverter. This inverter operated from the split capacitor DC link consisting of two active switches driven by a fixed duty ratio of 0.5. The autotransformer was also used to drive a sinusoidal current through the series resonant circuit. This was implemented by a rectification of the resonant current to generate the output voltage. Other than being used to generate the output voltage, the resonant current was also injected into the three-phase rectifier to modulate the supply voltages of such a converter resulting in high input power factor [21].

Furthermore, small signal model and dynamic analysis of the CISRC have been reported in [22] and [23] to control the the output voltage level. Onother works in [24] and [25] have shown that it was possible to remove the autotransformer through the inclusion of a straightforward high frequency transformer as shown in Figure 4, thereby reducing the weight of the converter [24], [25]. The full-bridge CISRC provides an alternative output voltage regulation via phase-shift contol and reduces the device current as experienced by the half-bridge configuration. Unfortunately, there have been no experimental verifications reported for the circuit topology.

Due to setbacks of the existing series circuit topology like being limited to regulate the output voltage at light or zero load conditions, the CIHRC as shown in Figure 5 was developed in [27]-[29] to solve the resonant current dependency problem of the series circuit configuration of resonant converter. Further advanced application of the proposed converter in line with the rapid development of wireless power transfer (WPT) is presented in [30]-[31]. This future innovative technology of WPT integrates the proposed threephase AC to DC CIHRC with its system to explore the possibility of supplying electric power especially for mobile or rotating devices without any wire or cable. As a result of this, additional isolation to the proposed converter model can be envisaged, ensuring a spark-free and maintenance-free system. Furthermore, the used of WPT technology can improve the reliability of such systems in critical applications such as robotics, biomedicine, aerospace and multi-sensor which can then set such devices or systems free from the inconvenient wires [26].

In this paper, the operation of current injection technique with the lossless zero voltage switching (ZVS) condition on shaping the high power factor of supply current waveforms are presented. With an appropriate design of hybrid resonant circuit and a suitable switching frequency selection, the devices is capable to operate under virtually lossless ZVS conditions with high frequency operation allowing reduction in the size of inductive and magnetic components. 


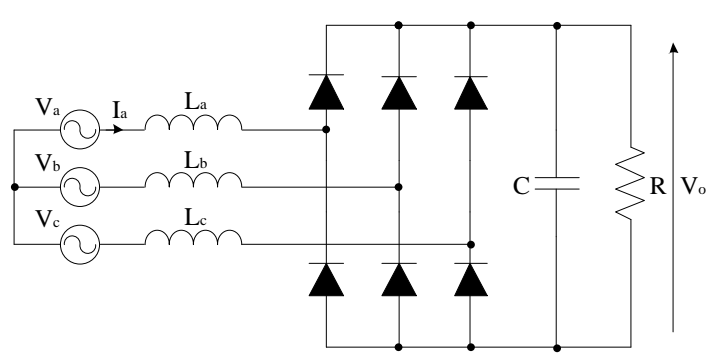

(a)

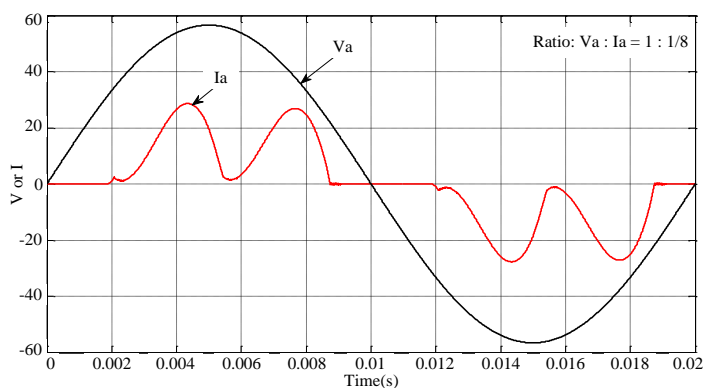

(b)

Figure 1. Three-phase rectifier (a) Circuit configuration, (b) Associated line current and voltage waveform

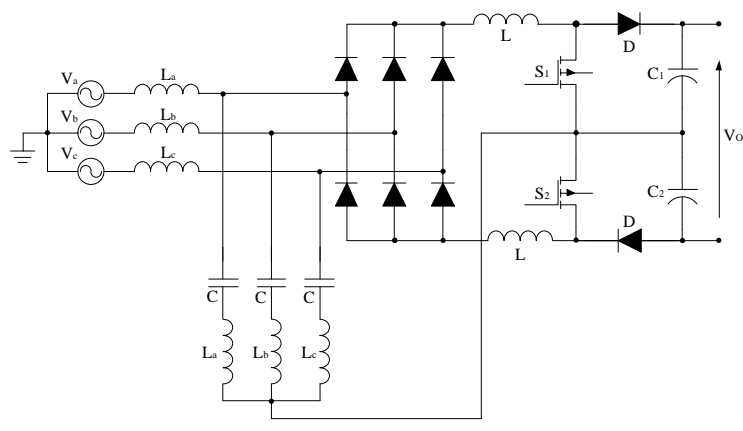

Figure 2. The current injection boost converter

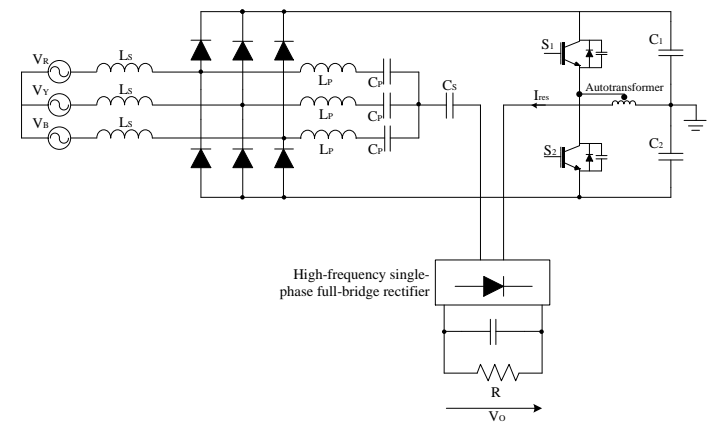

Figure 3. The CISRC circuit

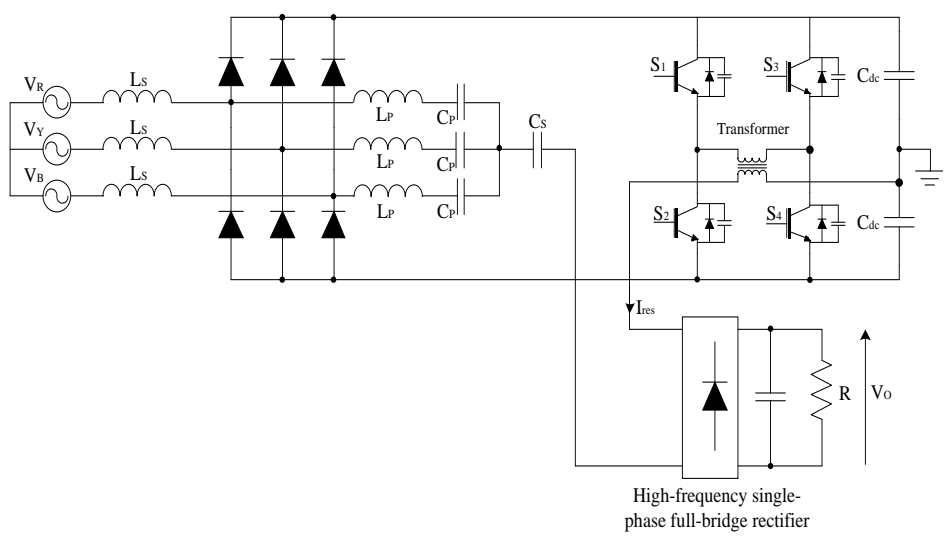

Figure 4. The full-bridge CISRC circuit

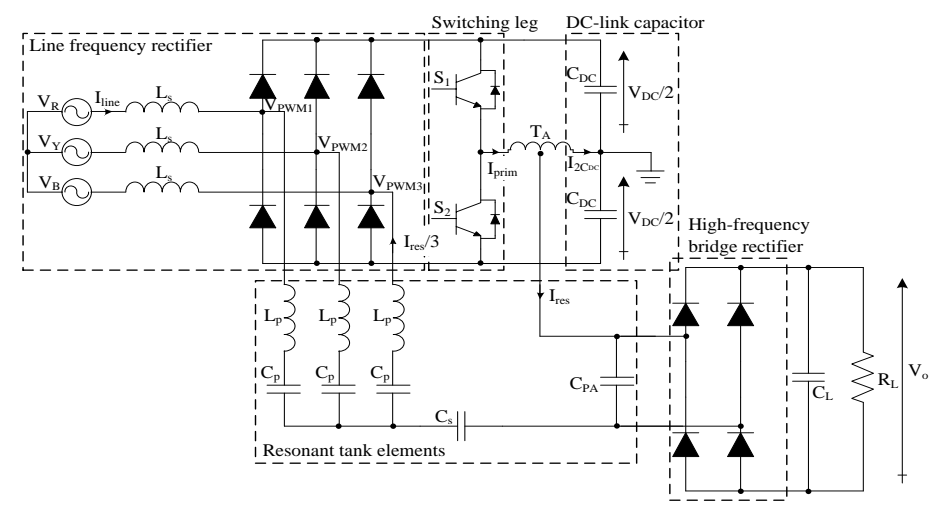

Figure 5. The CIHRC circuit 


\section{SOFT SWITCHING OF CIHRC WITH WPT FUNCTION}

The CIHRC with WPT function is shown in Figure 6 divided into two major components; a) transmitter circuit, and b) receiver circuit. In this work, the CIHRC technique was used to compensate the distorted supply current waveform in order to improve the power factor of the rectifier feeding a load comprising a resistor and a capacitor filter. The inclusion of the transmitter and receiver coils in the proposed three-phase AC to DC CIHRC could enhance the capability of the converter to supply electrical power to the load wirelessly. For this purpose, the capacitor $\mathrm{C}_{\mathrm{PA} 2}$ which use the same value with the capacitor $\mathrm{C}_{\mathrm{PA} 1}$ was connected in parallel with the receiver coil to obtain the same total impedance with the transmitter coil.

First, the utility AC supply was converted to a DC voltage using a three-phase diode bridge rectifier. Apart from converting AC supply to DC voltage form, it contributed to the distorted supply current waveform and low power factor. To solve this problem, the CIHRC technique was used to compensate the supply current waveform to become sinusoidal, continuous and in-phase with the supply voltage waveform. Then, the DC voltage was converted to a high-frequency AC voltage form. An autotransformer was used as part of the CIHRC circuit. The output of an autotransformer consisted of a resonant current, Ires and a switching leg voltage, $\mathrm{V}_{\text {DC-DC}}$. The high-frequency resonant current will flow through a transmitter coil thereby generating the alternating magnetic fields.

The purpose of receiver coil was to capture the oscillating magnetic field which in turn, generates or induces an electric current in the receiver coil. In the end, the AC voltage on the receiving coil was rectified to the DC voltage form. A DC capacitor was used to reduce the output voltage ripple before being connected to the DC load.

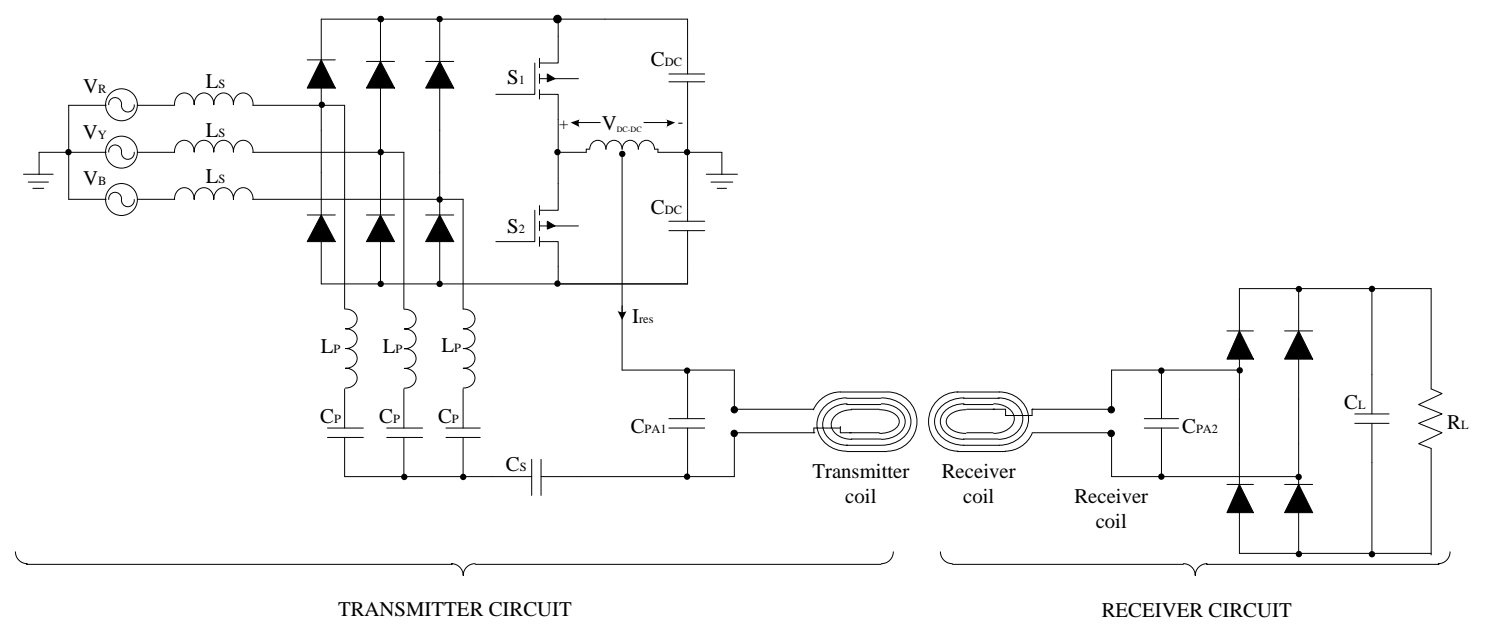

Figure 6. The CIHRC with WPT function

\section{RESULTS AND ANALYSIS}

Figure 7 shows the simulation results of the supply current and voltage waveforms. The result showed that the supply current was continuous, sinusoidal and in-phase with the supply waveform with the THD level is $2.71 \%$. Figure 8 shows that the comparison results of the harmonics spectrum of the supply current waveform with the IEEE Std 519. The comparison result clearly shows that the harmonic spectrums of the supply current waveform were well below the acceptable limit defined by the IEEE Std 519. The efficiency of the three-phase AC to DC CIHRC with WPT function of $92 \%$ was obtained with the power factor of 0.997 .

The simulation results of the resonant current Ires and voltage leg VDC-DC waveforms of the threephase AC to DC CIHRC with WPT function is shown in Figure 9. It can be seen that the resonant current, Ires lagged with the voltage leg, $\mathrm{V}_{\text {DC-DC. }}$ Figure 10 shows the output voltage waveform of the three-phase AC to DC CIHRC with WPT function. Figure 11 shows the simulation result of the upper switch, $\left(\mathrm{S}_{1}\right)$ and lower switch, $\left(\mathrm{S}_{2}\right)$ with PWM signal during positive and negative cycle operations respectively. Based on Figure 11, when the lower switch is turned-OFF, the resonant current cannot flow through the lower switch. Hence, the only path that the resonant current has is through the body diode of the upper switch which is illustrated by the negative current of $I_{s}$, results in the voltage across the upper switch $V_{D S}$ equals to zero. It can be observed that both switches perform their zero-voltage-switching, thus verified the soft switching transitions of the converter. 


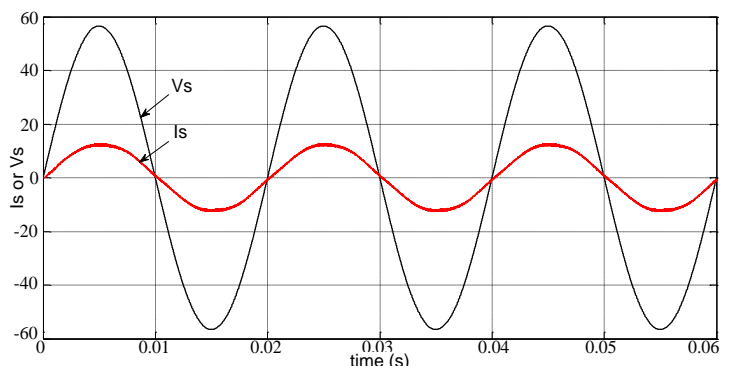

Figure 7. The red phase of supply current and voltage waveforms

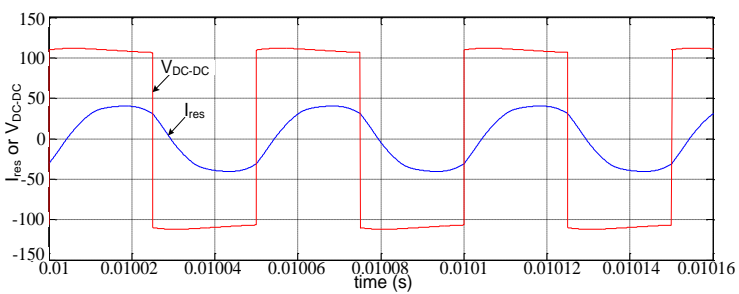

Figure 9. The resonant current Ires and voltage leg VDC-DC of proposed three-phase AC-DC CIHRC with WPT function

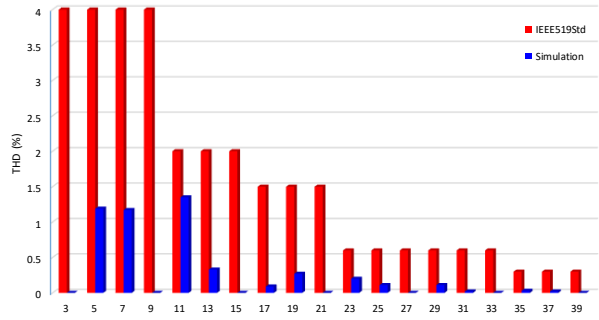

Figure 8. Comparison result of the harmonics spectrum of the supply current waveform with the IEEE Std. 519

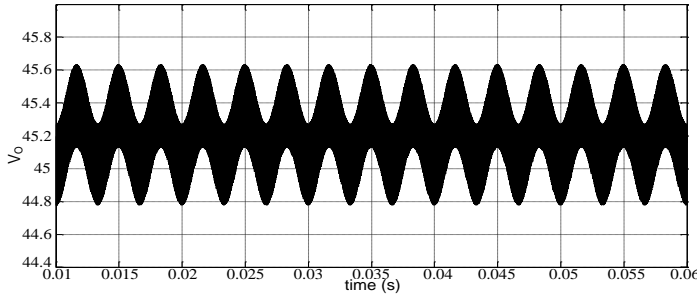

Figure 10. The output voltage waveform of threephase AC-DC CIHRC with WPT function

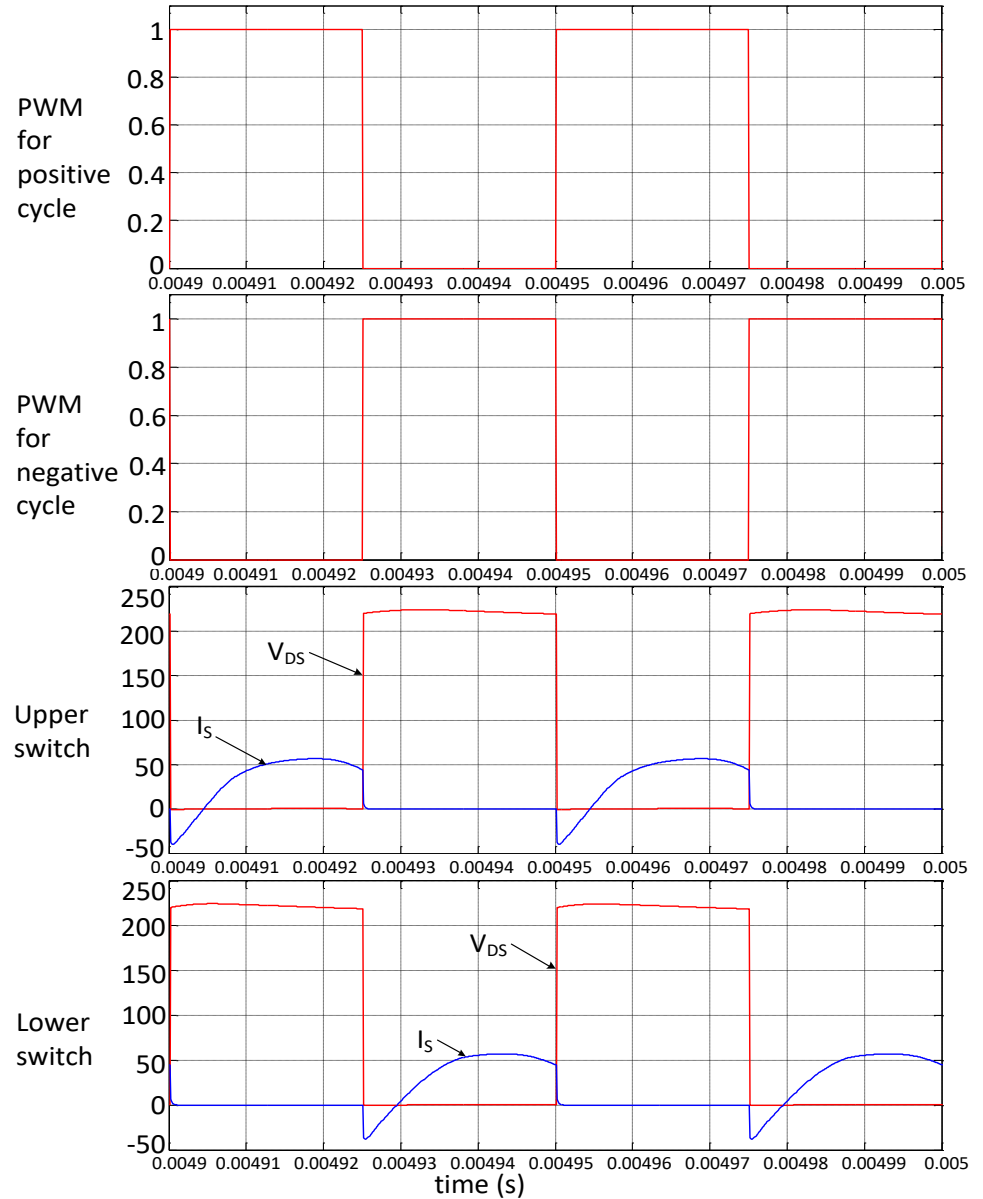

Figure 11. Simulation result of soft switching of $S_{1}$ (upper switch) and $S_{2}$ (lower switch) with PWM signal for the of three-phase AC to DC CIHRC with WPT function 


\section{CONCLUSION}

In this paper, verification of the soft switching lossless ZVS condition for the CIHRC with WPT function was presented. The performance of the converter has been evaluated by assessing the efficiency, the power factor and the THD. The supply current waveform of the CIHRC with WPT function resulted with an almost sinusoidal and in-phase with the supply voltage thus contributing to the low THD level of $2.71 \%$ which also satisfying the IEEE Std. 519. The maximum power transfer efficiency of $92 \%$ was achieved at a distance of transmitter and receiver coils of $5 \mathrm{~mm}$ and coupling coefficient of 0.54 . The comparison of the individual harmonic spectrum of the red phase supply current waveform with the IEEE Std. 519 showed that all of the harmonic spectrum were well below the acceptable limit and satisfied the standard.

\section{ACKNOWLEDGEMENTS}

Authors gratefully acknowledge the financial support from Institute of Research Management and Innovation (IRMI) Universiti Teknologi MARA Grant No: 600-IRMI/MyRA 5/3/BESTARI (029/2017).

\section{REFERENCES}

[1] J. Shah and G. Moschopoulos, "Three-Phase Rectifiers with Power Factor Correction," in Canadian Conference on Electrical and Computer Engineering, 2005., May 2005, pp. 1270-1273.

[2] D. Alexa, A. Sirbu, D. M. Dobrea, and T. Goras, "Topologies of Three-Phase Rectifiers with Near Sinusoidal Input Currents," IEE Proceedings - Electric Power Applications, vol. 151, no. 6, Nov 2004, pp. 673-678.

[3] H. Wang, M. Su, Y. Sun, J. Yang, G. Zhang, W. Gui, and J. Feng, "Two-Stage Matrix Converter Based on ThirdHarmonic Injection Technique," IEEE Transactions on Power Electronics, vol. 31, no. 1, Jan 2016, pp. 533-547.

[4] J. C. Pelicer, F. J. M. de Seixas, A. C. de Loureno, and L. d. S. d. C. e Silva, "Novel Isolated Multi-Pulse Rectifiers with Low Current Distortion using Three-Phase Half-Controlled Boost Converters," in 2015 IEEE 13th Brazilian Power Electronics Conference and 1st Southern Power Electronics Conference (COBEP/SPEC), Nov 2015, pp. 1-5.

[5] C. Rech and J. R. Pinheiro, "Line Current Harmonics Reduction in Multi-Pulse Connection of Asymmetrically Loaded Rectifiers," IEEE Transactions on Industrial Electronics, vol. 52, no. 3, June 2005, pp. 640-652.

[6] B. Singh, V. Garg, and G. Bhuvaneswari, "Polygon-Connected Autotransformer-Based 24-Pulse AC-DC Converter for Vector-Controlled Induction-Motor Drives," IEEE Transactions on Industrial Electronics, vol. 55, no. 1, Jan 2008, pp. 197-208.

[7] V. Vorperian and S. Cuk, "A Complete DC Analysis of the Series Resonant Converter," in 1982 IEEE Power Electronics Specialists conference, June 1982, pp. 85-100.

[8] H. Kanaan, K. Al-Haddad, R. Chaffai, L. Duguay, and F. Fnaiech, "Input/Output Feedback Linearization Technique Applied to a CITPR [Current-Injection Three-Phase Rectifier]," in 2001 IEEE 32nd Annual Power Electronics Specialists Conference, 2001. PESC. vol. 3, 2001, pp. 1321-1326.

[9] A. V. T.Chandrasekar, Dr. Justus Rabi, "A Study and Review of Current Injection Techniques," International Journal of Technology and Engineering Science [IJTES], Vol 1(6), Sept 2013, pp1008-10013.

[10] H. Kanaan, K. Al-Haddad, R. Chaffai, L. Duguay, and F. Fnaiech, "A Comparative Study of Hysteresis and PWM Control Techniques Applied to an Injection-Current-Based Three-Phase Rectifier," in Canadian Conference on Electrical and Computer Engineering, vol. 2, 2001, pp. 785-792.

[11] M. Y. Tarnini, "Harmonic Filtration by Current Injection and Shunt Capacitors Technique," in 2013 3rd International Conference on Electric Power and Energy Conversion Systems (EPECS), Oct 2013, pp. 1-5.

[12] M. Taleb and T. H. Ortmeyer, "Examination of the Current Injection Technique [Distribution Networks]," IEEE Transactions on Power Delivery, vol. 7, no. 1, Jan 1992, pp. 442-448.

[13] H. Y. Kanaan and K. Al-Haddad, "Three-Phase Current-Injection Rectifiers: Competitive Topologies for Power Factor Correction," IEEE Industrial Electronics Magazine, vol. 6, no. 3, Sept 2012, pp. 24-40.

[14] P. Pejovic, P. Bozovic, and D. Shmilovitz, "Low-Harmonic, Three-Phase Rectifier that Applies Current Injection and a Passive Resistance Emulator," IEEE Power Electronics Letters, vol. 3, no. 3, Sept 2005, pp. 96-100.

[15] B. M. Bird, J. F. Marsh, and P. R. McLellan, "Harmonic Reduction in Multiplex Convertors by Triple-Frequency Current Injection,” Proceedings of the Institution of Electrical Engineers, vol. 116, no. 10, October 1969, pp. 17301734.

[16] A. Ametani, "Harmonic Reduction in Thyristor Converters by Harmonic Current Injection," IEEE Transactions on Power Apparatus and Systems, vol. 95, no. 2, Mar 1976, pp. 441-449.

[17] A. I. Maswood and E. Firmansyah, "Simple Current Injection Technique for Power Factor Correction in Controlled Rectifier Applications," IEE Proceedings-Electric Power Applications, vol. 152, no. 2, March 2005, pp. 249-260.

[18] A. I. Maswood and E. Firmansyah, "Novel Current Injection Technique in Controlled Rectifier," The Fifth International Conference on in Power Electronics and Drive Systems, 2003. PEDS 2003. vol. 2, Nov 2003, pp. 1070-1074.

[19] R. A. Rached, H. Y. Kanaan, and K. Al-Haddad, "Three-Phase Rectifier with an Active Current Injection and a Single High-Frequency Inductor," in 2010 IEEE Energy Conversion Congress and Exposition, Sept 2010, pp. 2074-2078. 
[20] M. N. Seroji, "Analysis and Control Design of a High-Power Factor, Three-Phase AC/DC Converter with HighFrequency Resonant Current Injection," Ph.D. dissertation, Department of Electronic, Electrical and Computer Engineering, University of Birmingham, December 2007

[21] A. M. Cross and A. J. Forsyth, "A High-Power-Factor, Three-Phase Isolated AC-DC Converter using HighFrequency Current Injection," IEEE Transactions on Power Electronics, vol. 18, no. 4, July 2003, pp. 1012-1019.

[22] M. N. Seroji and A. J. Forsyth, "Small-Signal Model of a High-Power-Factor, Three-Phase AC-DC Converter with High-Frequency Resonant Current Injection," in 2005 International Conference on Power Electronics and Drives Systems, vol. 1, 2005, pp. 462-467.

[23] M. N. Seroji and A. J. Forsyth, "A Simple Direct-Frequency Control of AC/DC Three-Phase Current Injection Series Resonant Converter (CISRC)," in IEEE Symposium on Industrial Electronics Applications, 2009. ISIEA 2009. vol. 2, Oct 2009, pp. 652-657.

[24] M. F. Omar, M. N. Seroji, and M. K. Hamzah, "Analysis and Simulation of Three-Phase AC/DC Full-Bridge Current Injection Series Resonant Converter (FBCISRC)," in 2010 IEEE Symposium on Industrial Electronics Applications (ISIEA), Oct 2010, pp. 159-164.

[25] M. F. Omar, M. N. Seroji, and M. K. Hamzah, "Analysis and Simulation of Phase-Shift Control for Three-Phase AC/DC Full-Bridge Current Injection Series Resonant Converter," in 2012 IEEE Symposium on Industrial Electronics and Applications (ISIEA), Sept 2012, pp. 114-117.

[26] M. P. Kazmierkowski and A. J. Moradewicz, "Unplugged But Connected: Review of Contactless Energy Transfer Systems," IEEE Industrial Electronics Magazine, vol. 6, no. 4, Dec 2012, pp. 47-55.

[27] Rahimi Baharom, Mohammad Nawawi Seroji and Mohd Khairul Mohd Salleh, "Computer simulation model and performance analysis of high power factor three-phase AC-DC current injection hybrid resonant converter", 2015 IEEE 10th Conference on Industrial Electronics and Applications (ICIEA), Pages: 1403 - 1407, Year: 2015.

[28] Rahimi Baharom, Mohammad Nawawi Seroji, Mohd Khairul Mohd Salleh, Khairul Safuan Muhammad, "A high power factor three-phase AC-DC current injection hybrid resonant converter", IECON 2016 - 42nd Annual Conference of the IEEE Industrial Electronics Society, Pages: 3123 - 3128, Year: 2016.

[29] Rahimi Baharom, Mohammad Nawawi Seroji, Mohd Khairul Mohd Salleh, Ihsan Mohd Yassin, "Steady-state Analysis of Three-Phase AC to DC Converter using Current Injection Hybrid Resonant Converter for Power Factor Correction”, 2016 7th International Conference on Intelligent Systems, Modelling and Simulation (ISMS), Pages: 256 - 260, Year: 2016.

[30] R. Baharom and M. N. Seroji; "Modelling And Simulation of High Power Factor Three-Phase AC-DC Converter With Wireless Power Transfer Function Using Current Injection Hybrid Resonant Technique"; Journal of Fundamental and Applied Sciences, Vol.10, No.6S (2018), Pages: 646 - 657, March 2018.

[31] R. Baharom, M. N. Seroji, K. S. Muhammad and N. F. N. Ismail; "Three-Phase AC to DC CIHRC with Wireless Power Transfer Function”; Journal of Fundamental and Applied Sciences, Vol.10, No.6S (2018), Pages: 669 - 680, March 2018.

\section{BIOGRAPHY OF AUTHOR}

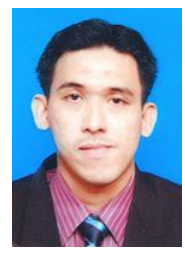

R. Baharom received his B.Eng. degree, M.Sc. degree and Ph.D. from Universiti Teknologi MARA, Malaysia in 2006, 2009 and 2018 respectively. From 2005 to 2009, he was a research assistant at Institute of Research, Development and Commercialization (IRDC) Universiti Teknologi MARA, Malaysia. He is now a senior lecturer at Faculty of Electrical Engineering, Universiti Teknologi MARA, Malaysia. His research interests include AC-DC converter, wireless power transfer, medium-voltage medium-frequency solid-state transformer, resonant converter with advanced control, and single-phase matrix converter. 